\title{
God's health and human health: A proposal for the world of well-being
}

\section{Author:}

J. Harold Ellens ${ }^{1,2}$

Affiliations:

${ }^{1}$ Department of Near

Eastern Studies, University

of Michigan, United States

${ }^{2}$ Faculty of Theology,

University of Pretoria,

South Africa

Note:

J. Harold Ellens is Executive Director Emeritus of the Christian Association for Psychological Studies, Founding Editor and Editor in Chief Emeritus of the Journal of Psychology and Christianity, a retired Presbyterian theologian and pastor, and a licensed psychotherapist. He holds graduate degrees of MDiv from Calvin Theological Seminary, an MTh from Princeton Theological Seminary, and a PhD from Wayne State University. This article is a reworked version of a chapter which was originally delivered as an address to the Wellbeing Conference at the Claremont Graduate University. The sehtiments expressed in the article have been published elsewhere by the author, but are used here for the first time in such a comprehensive form. This article is dedicated in honour of the author's friend Professor Andries van Aarde, co-participant in amongst others, the Society of Biblical Literature's 'Bible and Psychology Section' and Praeger Perspective's four volume Psychology and the Bible: A new way to read Scriptures (2004), edited by J. Harold Ellens and Wayne G. Rollins. Prof. Dr J.H. Ellens is participating as research associate of Prof Dr Andries G. van Aarde, honorary professor at the Faculty of Theology of the University of Pretoria, South Africa.
This article reflects on people's presuppositions with regard to God's mental health as it has been recounted throughout history. The article asserts that the dominant report of a 'sick god' has nothing to do with God at all, but is, instead, the manifestation of a sick projection of people who are terrified of the unknown and the unpredictable in life. Such a projection reflects their own fears, which they project upon their own mental image of the mentor who they thought was God. The other, sound, report on God's mental health has encountered many difficulties in competing with the dominant report. The alternative report has met with much resistance, because it seems so humanly unbelievable, in its claim that God is a God of unconditional grace to all humankind.

\section{The sickness of God}

For much of the last 4000 years, 'God' has been deemed critically ill, in most people's perspective. That is, the reports on his nature and function indicate that his patterns of relationality, affect, and ideation have been considered to be beyond normal range. To be very specific, apparently 'God' has suffered from chronic paranoid schizophrenia, or severe borderline personality disorder, with frequent erratic, that is, unprovoked episodes of active psychosis. The dominant stream of reports indicates that he operates with the psychotic notion that he is caught in a cosmic battle with another god, who threatens to thwart, corrupt, and undo his work. Such are symptoms of a classic psychotic syndrome, in that, according to the reports, they form a global ideation, which shapes his entire world view, whereas there are no empirical, heuristic, or phenomenological data to indicate that any such cosmic conflict or evil reality actually exists. His notion of reality has no reality in the real world to which it corresponds. Moreover, such a pattern of ideation is specifically paranoid, as it indicates that he thinks there are forces 'out there' that are intent upon securing his downfall, whereas there is no evidence that such forces, in fact, exist. If the reports about him are accurate, these notions are figments of 'God's' sick imagination. 'God' is, according to such accounts, insane. The 'God' of ancient Israelite religion, which produced Judaism, Christianity, and Islam, is diagnosably ill in terms of the rubrics of the Diagnostic and Statistical Manual of Mental Disorders, which is published periodically by the American Psychiatric Association.

Sick gods make for sick people. To put it slightly differently, sick gods make people sick. As children and disciples model after their parents and mentors, so do individuals and communities of humans create themselves in the images of their gods. Sick gods provide sick models, which produce sick persons and sick communities. To ensure personal and communal well-being requires that one's god be well, or, at least, the converse is so. If one's god is sick, one cannot achieve well-being, either individually or communally.

Now you may feel that, somehow, I am too severe in my clinical diagnosis. Therefore, let me recite a more palpable panoply of symptoms which, according to the dominant reports, constitute the syndrome of god's clinical disorder. He is reported to suffer from a perfectionistic need to have his world, and all who happen to wander through it, carefully conform to a prescribed set of thought forms and behaviour. Such a requirement sounds rather obsessive compulsive, to say the least; particularly when you consider that the world he created is not a production factory, or forced labour camp, but was designed by 'God' to resemble more closely a greenhouse, in which the primary style and objective is that of growth and development, which necessitates a constant process of unpredictable change and experimentation. Perhaps you have not taken the reports of his demand for conformity so seriously as to have been much affected by this pathological symptom. What, then, of the reports that 'God' is so upset about human nature and behaviour, human exploration and experimentation, that he simply cannot correct his attitude until he has literally killed somebody? 


\section{Correspondence to: Andries van Aarde \\ email: \\ andries.vanaarde@up.ac.za \\ Postal address: \\ Faculty of Theology, University of Pretoria, Lynnwood Road, Hatfield \\ 0083, Pretoria, South Africa \\ Dates: \\ Received: 24 Mar. 2010 \\ Accepted: 30 May 2010 \\ Published: 07 June 2011 \\ How to cite this article: Ellens, J.H., 2011, 'God's health and human health: A proposal for the world of well-being', HTS Teologiese Studies/Theological Studies 67(1), Art. \#819, 6 pages. DOI: $10.4102 /$ hts.v67i1.819}

(C) 2011. The Authors. Licensee: OpenJournals Publishing. This work is licensed under the Creative Commons Attribution License.
Take all of Noah's community, for example, or Onan and his brother, or the Egyptian army at the Red Sea. Think of the threatened genocide of the Israelites at Mount Sinai; the genocide of the Canaanites upon the Israelite invasion of the former's land; the extermination of the Northern Israelite Kingdom; the exile of the Southern Israelite Kingdom; the sudden death of the man who tried to protect the Ark of the Covenant from falling into the mud; and the incineration of Sodom and Gomorrah.

If such events do not sound to you like a pattern of consummate narcissism, chronic situation inappropriateness, sadistic vindictiveness, impulsiveness and obsessive compulsive disorder, depressive and irrational rage, as well as signs of being out of touch with reality and out of proportion to the actual problematic events at hand in each case, you have not been paying attention. At the least, you have not been reading your Bible regularly. The behavioural syndrome I have just described is, clearly, a psychosis. Moreover, what about the fact that his fury was so intense towards you and me, innocent as we are, that he either had to exterminate us or slaughter his unique Son, Jesus of Nazareth. If the reports are true, this 'God' is one sick puppy, and dangerous to boot. After all, he resolves all his ultimate impasses with the utmost violence. Do you not think that that is sick? Any god who cannot behave at least as well as an average human being would like to is a monster. Monster gods make monster people.

Earlier, I referred to human beings as innocent. You might disagree. I concede that the only evil which exists in our world is the evil we do to one another. However, when I claim innocence, I mean to call attention to the fact that we humans did not ask to be born. We did not ask to be limited. We did not ask to be flawed. We did not ask to be developmental and, therefore, inherently and inevitably incomplete, with an ability to grow, to change, to achieve by trial and error, to experiment, to explore, and sometimes to run down dead-end streets morally, relationally, psychologically, and spiritually. We did not ask to be floated upon the ocean of time and space with an inadequate database, as well as immature judgment, and emotions which are often driven by anxiety about it all. We did not ask to be assigned a divine task of making sense of, and finding meaning in, the world in which we live, while being compelled to operate with mere human resources.

The worst of all this is that religious metaphors that we have been given in the dominant report about God's nature and behaviour tend to produce unconscious psychological archetypes in human beings, which are acted out unsuspectingly in behaviour that is justified in terms of such metaphors. If God solves all his ultimate problems by quickly resorting to ultimate violence, how is it possible that we can expect ourselves to act significantly differently? Sick gods make sick people. If God persuades us of his psychotic notion that he is caught in a cosmic conflict, the battleground of which is human history and the human heart, we shall, inevitably, wish, either unconsciously or consciously, to help him out; to be on his side in the war; to undertake God's cause against the infidel; to fight the bad guys, and to exterminate our enemies, as apparently God tries to do with his.

This is the flag under which ancient Israelite campaigns were fought against the Canaanites, and which make one often wonder about Israelite campaigns today. This is the flag under which the Christian campaigns of the Crusades were fought, which makes one often wonder about the rightwing Christian crusades today. This is the flag under which Islam conquered the Mediterranean world in the 7th and 8th centuries, and it is clear that we need not wonder at all about the al Qaeda ambitions of today. A sick god produces sick people. How shall we achieve well-being if 'God' is sick? We shall not, under any circumstances!

\section{The alternative account}

There was, of course, another report on God's mental health, though such a reports has been heavily discounted throughout history, often to the point of scoffing disbelief. It is the claim that the dominant and omnipresent report of the sick god has nothing to do with God at all, but is instead the sick projection of a great many untutored human imaginations. It has been produced by people who are terrified of the unknown and the unpredictable in life. It is a projection of their own terrors upon their own idealised mental image of the mentor who they thought was God. The alternative report on God's mental health has struggled to compete with the dominant 
report, even though the evidence confirming the truth of the former report is omnipresent. The resistance to this report is because it seems so humanly unbelievable, with its claim that God is a God of unconditional grace to all humankind.

Carl Rogers did not think that it was an inherently unbelievable idea that humans could exercise unconditional positive regard for one another, even if doing so often seems a very rare and rather unnatural occurrence. However, even he was most hesitant to believe it true of God. He said he abandoned his fundamentalist evangelical roots because the dominant report of the insane God was endemic to any religious thought, as he saw it. Consequently, he could preach human unconditional grace, but could not imagine God to have such unconditional grace. Rogers was unable fully to comprehend the message conveyed in Genesis 12 and 17, and Abraham's breakthrough notion of what God really is trying to communicate to the human race:

I am announcing to you that I will be a God to you and to your children after you, throughout their generations, for an everlasting covenant, no strings attached. You will be my people and I will be your God, and that is all there is to it.

He just could not imagine the kind of God whom we meet in Micah 7:18-20.

Carl Rogers could not repress the dominant report ringing in his ears, despite the fact that it was a false report. So he could not hear the strains of that grace refrain playing all the way through the Old and New Testament, declaring, as did the prophet Micah (7:18-20):

Who is a God like our God. He pardons iniquity. He passes over transgression. He will not be angry forever. He delights in steadfast love. He will have compassion on us. He is faithful to us when we are unfaithful to him. He tramples our iniquities under his feet, and casts all our sins into the sea of his eternal forgetfulness. Moreover, he guaranteed to us that we are forgiven before we were born and before we could imagine how to be clever sinners.

Unfortunately, Carl Rogers is joined by much of the human race throughout history, who cannot imagine that God is not insane. He could not imagine that St. Paul knew something essential about God's nature and behaviour, when he declared doxologically, 'I am persuaded that nothing in all God's creation can separate us from the love of God' (Rm $8: 28)$.

Now, that is a fairly healthy God. God, the warrior, the vindictive judge, the impulsive slayer, the genocidal maniac, is a monster, whom nobody should honour. He makes me sick! He makes us all sick. God, the purveyor of unconditional grace, is situation-appropriate. That is a key gradient of good mental health. We are human. We did not ask to be human; to be born; to be limited in our database; to be creatures of growth and change, and to be unfolding persons who inherently need to explore, to experiment and to imagine by trial and error. We did not ask for our transcendental task, and our mere mundane resources. Any God who does not see that and respond with unconditional positive regard is a very sick monster. That is why John says that the real God is faithful and just to forgive us! (I Jn 1:9). Did you hear that? It is a matter of justice that, for the likes of us, caught in our limited humanness, the only right thing is mercy. 'As a father pities his children so God pities us who contemplate him as awesome!' (Ps 103:9). Now, that is a healthy God.

\section{Understanding the implications of the alternative story}

We are all interested in human well-being, indeed, in the well-being of the entire cosmos, which, of course, depends largely upon how well we look after human well-being. I have argued so far that our well-being depends directly upon God's well-being. That is, we are addressing the problem of God's health and human health, which I have translated into the issue of God's grace and human health. What can we do to ensure that the report on God's nature and behaviour tells the story of his robust health and inherent good will toward us - thereby ensuring that our base of operations and our basic assumptions will enhance human well-being - instead of the lie that he is a monster?

To put the question in a more operationally clinical and scientific form: How can we bring good theology and responsible psychology into that kind of authentic interface in which they mutually illumine each other, so as to enlighten our interpretation of human nature. Human beings are living human documents, in which is written the story of God's creative vision and of our enquiring quest for meaningful life. How can we bring theology and psychology to bear on the interpretation of the living human document in such a fashion as to know what will produce our true well-being? Well-being is a matter of body, mind, and soul, meaning that it is a matter of the economy, of academics, of the intellect, of aesthetics, and of spirituality. I am thoroughly convinced that psychology and spirituality are two terms for the same domain. Each has its own universe of discourse and, therefore, its own modus operandi, but the domains of psychology and spirituality are the same. That domain is constituted by the complex panoply of critical aspects which shapes the irrepressible human quest for mundane and transcendental meaning.

Psychologists who do not take seriously the light that human spirituality can bring to bear upon the scientific discipline of psychology are simply not truly serious about either their own profession, or their own psychology. Theologians who do not take seriously the light that human psychology can bring to bear upon the scientific discipline of theology are simply not truly serious about either their own profession, or their own spirituality.

The sciences of psychology and theology, practised properly and responsibly, inevitably interface at four scientific levels: theory development; research models; data management, and clinical application. At each such level, the anthropological model forms and functions, in terms of which psychology and theology interface. Each brings to bear its distinct light for the illumination of the real and comprehensive nature of 
the living human document that is the subject of the scientific work of both. Moreover, within the anthropological model to which both psychology and spirituality, or its scientific instrument, theology, contribute, it is the personality theory that forms and functions there that is the central site of the mutual illumination the two sciences offer.

An illustration of what this means and how this works might be developed upon the basis of an ancient biblical story that, in its historic reading, has seemed to report that God is sick, establishing a religious metaphor that has produced really sick human archetypes and sick humans for 3000 years. That is the story, which can be found in Genesis 3, regarding the Fall of Adam and Eve, their expulsion from the idyllic world of Eden, and their being cursed by God. There is another way in which to read the story concerned. As it stands, it is a rewrite in Hebrew parlance of a much more ancient Mesopotamian fertility myth. The symbols are those of the fruitful tree, the virgin seducing and being seduced, the phallic symbol snake, and the triple seduction: the snake and Eve mutually seducing each other, and Eve's seduction of Adam. Read literally, in terms of long-standing theological tradition, the account is relatively superficial, telling of how our first parents disobeyed a specific arbitrary divine command. In response, God became furious, threw them out of Paradise, and cursed humanity. Such a reaction would appear to be evidence of the monster God.

If one asks why the ancient Hebrews so approved of the above tale that they adopted it, the answer is obvious. They had a monster God. They experienced the world as being both profoundly troubled, and in trouble. They had the option of accusing God of having created it that way, as they did in their older narrative in Genesis 6, or of releasing God from his responsibility by accusing themselves in this respect. The one truth which they recognised throughout the saga was that anyone reading the story of Adam and Eve should immediately be able to acknowledge that it describes our real-life experience. Life is troubled; we feel inadequate and ashamed about our inability to cope with all difficulties as masterfully as we should; we long for love and meaning; we are deeply concerned about out sexuality and spirituality; we feel cast out of, or alienated from, our true destiny; and we long for close fellowship with our father, but seem unable to come close to him. In short, the ancient Hebrews knew the story somehow rang true in relation to some of our worst perplexities. We are lost souls, and we are at a loss. The ancient Hebrews did not know that there was another way in which to read such a story.

The ancient Hebrews assumed the dominant story about a threatening God was the model of reality. However, if we bring the other report to bear on such a story and illumine it with a sound psychological perspective, it is readily evident that the story is about the inevitable adolescence of the human race. It is a story about leaving the womb and the nursery; exploring the possibilities of our own personhood; discovering the knowledge of our potential for good and for evil; and disclosing to ourselves the meaning of our sexuality, spirituality, and individuation. With the mutual illumination of sound psychology and good theology, the story becomes the poetic suggestion that Adam and Eve needed to assert their individuality against the constraints of parental, even divine, authority in order to find their true selves. The enigma in the narrative of Genesis 3 is in the realisation that the Fall was a necessary act of growth, and raises the question as to whether the above-mentioned adolescent process for persons and communities is best achieved by evolution or revolution.

Adam and Eve chose to revolt. The narrative, properly illumined by good theology and good psychology, is not a story about God cursing them for doing so. The narrative is about living with the inevitable consequences of the necessary and unavoidable choices that growth requires. Such choices must be made without adequate knowledge of the future, without adequate insight about our options and alternatives, and without sufficient knowledge of the ambiguity of adult responsibility. God's remarks upon their escape from infancy do not take the form of a curse prescribed, but the form of a destiny described, namely, that adult life is bound to be painfully hard work.

An appropriate mutual illumination of our psycho-spiritual metaphors and the archetypes which they produce, offers us a healthy God, who is a model for healthy people. I mean this not as a liturgical litany - I mean it as a clinically operational fact. Human well-being depends upon good theology and sound psychology, which, in unison, can produce a whole spirituality. Spirituality, as seen in this way, is not a mere transcendental myth, but, rather, is the function of the inner person in the quest for the living human document to be thoroughly inscribed with the cadences of the poetry and music of truly fulfilling meaning. The reference here is to a kind of well-being which encompasses wholeness of personhood and community, and one which derives from a comprehensive and satisfying sense of the meaningfulness of life, both individually and in relationship. Spirituality is the universal human hunger for meaning, whether at the level of the mundane, the transcendent, or the eternal.

Such spirituality is possible for all humanity, including for you and me, for George Bush, for al Qaeda, and for the Democrats. However, it must be borne in mind that the 15\% of every human community which suffers from inherited severe borderline psychosis is unable to participate in such spirituality, except with appropriate medication. (For further clarification of this point, as in direct reference to al Qaeda, see below.) The development of a psycho-spiritual strategy, and its attendant psycho-social programme, reflects a thoroughgoing grace perspective or unconditional positive regard for one another, against the backdrop of the conviction that such a position of unconditional grace is the real story about God. Such a strategy or programme might so shape our assumptions about personality theory and anthropology that it will allow for the fashioning of a new global model of constructive relationality. The development of such a strategy or programme is essential for human well- 
being, as, without it, we would continue down the trajectory of ever-increasing processes which would, inevitably, up the ante of violence. Such a strategy or programme must be grounded in a wholesome psycho-spiritual model. Islamic fundamentalists have done us a great favour, namely, they have pitched to us the clear signal that what shapes human meaning is the issue of whether God is sick or well.

Such an honest psycho-spiritual way of reading the story of God acknowledges that the problem of human unwellbeing, in the form of human dysfunction, is not the problem of sin, in the modern, moralistic construction of that concept, but, rather, the problem of sickness, human inadequacy and incompleteness. Such problems hamper our ability to respond appropriately to the responsibilities of life and to the challenges of godliness. We are not so much perverse as we are under-evolved.

An operational model of such a unique kind of personal and global relationality should, at the very least, have the following ten practical characteristics. Firstly, the model requires the incarnation, within the personhood of each one of us, a genuine passion about the new initiative of unconditional acceptance of the adversary or diverse other. Such unconditional acceptance means affirming the other person, wherever that person or community is at the present moment in his or her health or malignancy of spirit.

Secondly, the model requires the possession of a profound empathy, which places the one who cares within the frame of reference of the diverse or alienated other person or community (read al Qaeda, for example). Such empathy should lead the caring person to discern the sources and nature of the obstructions to grace-filled relationality which are suffered by the diverse other, as well as to be capable of suggesting possibilities for overcoming alienation. Such unconditional grace affords the alienated person or community the potential for the development of a new sense of self-worth, of wholesome meaning, and of a healthy Godstory.

Thirdly, such an initiative would provide persons and communities with a sense of mutuality in their quest for well-being. Fourthly, it would imply acknowledging that the caring initiator also comes to the relationship with human impairments.

Fifthly, in this context, the caring person's and community's world view would hereby be able to express a comprehensive ambition for the attainment of the wholeness of the whole world of humans and things, as well as evidence of the diverse other's well-being being sought in such a setting. Sixthly, the development of such a model should make apparent that the mutual growth of both persons and communities is a real and expected possibility.

Seventhly, both the persons and the communities concerned should, in terms of such a model, be able to realise operationally the extent to which human well-being depends upon the health of the God which each party envisions.
Islam has, for many centuries, had such a view of Allah as has had the capacity to prompt the development of a richly wholesome culture and a relationality with Jews and Christians. The Medieval Spanish Islamic Caliphate was but one example of such a development.

Eighthly, it may be anticipated that such a strategy would evoke the level of security and trust which sets aside defensive patterns on both sides, and which is intent upon defeating any obstructions to mutuality, growth, wholeness, and well-being. Ninthly, both persons and communities might realise, in terms of such a strategy, that they are being taken seriously and affirmed.

Tenthly, the effectiveness of the journey in unconditional positive regard which is considered here could be measured and critiqued psycho-spiritually at each step along the way. The standard for such a critique would be the expectation of the realisation of the ultimate achievement of mutual wellbeing. Such a vision would be one of mutual psycho-spiritual maturity. Such maturity would bring the benefits, materially and economically, academically and intellectually, and aesthetically and spiritually, which would represent true wholeness.

The above-mentioned diverse others might be relatively benign colleagues, who are engaged in a vigorous dialogue, in which significant polarity is evident between the views presented. They might even, in contrast, be lethal opponents who are engaged in military, political, and cultural conflicts, such as that which is waged between al Qaeda and the West today. In the latter case, particularly as it applies to al Qaeda, the diversity and lethality of the conflict might be driven by one or more of the following dynamics. Firstly, it might be that the adversary is afflicted with borderline or active psychosis, as diagnosed in terms of the 4th edition of the Diagnostic and Statistical Manual of Mental Disorders. If that is what we are up against in such a case, mere dialogue and negotiation is likely to be fruitless. Only medication of such pathological persons will work to produce such constructive management of the symptoms concerned that mutuality will be made possible. Short of proper medication, the only course of action in such a case is the tough love approach of imposing such boundaries upon the persons concerned as to prevent them from causing mayhem on both the societal and the personal front.

Secondly, the motive of such individuals might be the legitimate socio-political objective of preserving the umma, meaning the Islamic community or nation, from incursions and erosions resulting from the development of Western military or commercial or industrial interests. Such Muslims might resent the unwelcome, society-opening influences that always accompany such incursions.

Thirdly, the adversaries concerned might be motivated by legitimate anguish and fear regarding the trivialisation of Islam's spiritual or cultural ideals and values. Such trivialisation might result from the impact of unsystematised 
Western cultural artefacts, and the trivial secular values which they convey, on Islamic culture and spirituality.

The present world conflict, which has taken the form of international violence and terrorism, is, currently, the most dangerous threat to human well-being worldwide. Such a danger is accompanied by the alarming increase in the number of people suffering from the Acquired Immune Deficiency Syndrome (AIDS), in addition to the wastage of resources which might, otherwise, have been invested in developments in the medical, mental health, and education fields, as well as the creation of the modern-day culture of aesthetics. All such threats continue to violate and erode human well-being, because both our unconscious and our conscious psycho-spiritual models and archetypes are formed along the axes of vindictiveness and quid-pro-quo strategies, the settling of scores, the imposing of boundaries upon persons and communities to force discipline upon them, the meeting of force with force, and the doing unto others what we would not have them do unto us, while making sure, in terms of the doctrine of pre-emptive defence, that we do it to them first. Such archetypes of fighting fire with fire are products of unconscious metaphors, which state that the world is wired for this violence. We slide into the assumption that the cosmos is wired accordingly, and that God is also wired in this way. If we have a major problem, we feel that we may resort to ultimate force. If God does, why should not we. It's how things are wired. God was so disturbed with us that he could not get his head screwed back on straight until he had killed somebody, either us or his unique Son. Humans readily think that such is the familiar way in which things are set up.

Merely resorting to current psychological models will not enable us to respond adequately to the deep structural challenges which require the real work. Al Qaeda will continue to find ways in which to fight for Allah as long as the belief persists that Allah is the God of jihad and fatwa, bent on exterminating infidels in the Muslim umma. Such an approach is no different to that which was taken in the Christian enterprise of the Crusades of the 12 th century CE, in terms of which their warrior God was regarded as intending his minions 'to deliver the Holy Places from the Infidel Turk'. One is led to wonder about present-day crusading spirits. Such belief is no different than the Israelite conviction that, because it was the mandate of God, they should engage in the ethnic cleansing of Canaan during the 12th century BCE. With a similar theology and psychology, the modern-day Israelites most probably conceived of the strategy of preemptive defence.

\section{Conclusion}

No soft-headed trivialisation of the problem by psychologising or spiritualising it in a Sunday School kind of superficiality has been proposed in this paper. The extent of the challenge is also not underestimated. What is proposed here is more in line with the hard-headed, aggressive rationalism of Ayn Rand than it is in line with the manipulative sentimentality of contentious, soft-headed Western-style liberalism.

We shall not achieve human well-being until we create a world culture of well-being. We shall not achieve that until our gods grow well. A world culture of well-being implies a world of psycho-spiritual metaphors that produce healthful, unconscious archetypes. To achieve that we must destroy the sick monster God that reigns unconsciously in the hearts of all three of the religions derived from the Old Testament story. The programmes of psychological and moral reframing that are proposed in the current paper are worth the trouble. Although Freud and Jung have helped us a great deal, it is the monster God that must be exorcised and killed. The healing God of radical, unconditional, and universal grace must be let loose on the world if we are to progress towards the world of well-being that we can imagine, instead of persisting in the lethal world which we continually tend to create. 